\title{
0 LÚDICO E OS (DES)CAMINHOS HISTORIOGRÁFICOS DA LITERATURA INFANTO-JUVENIL NO BRASIL
}

http://dx.doi.org/10.11606/issn.2237-1184.v0i24p98-113

\author{
Danglei de Castro Pereira ${ }^{1}$
}

Universidade de São Paulo

RESUMO

Este texto aborda aspectos da historiografia literária brasileira como ponto de partida para uma reflexão sobre o lugar da literatura infanto-juvenil no âmbito da historiográfica literária e, posteriormente, a relevância do lúdico, conforme Huizinga (2004), na construção estética destes textos. Nosso objetivo é abordar a relevância estética da literatura infanto-juvenil por meio da focalização de poemas de José Paulo Paes e Jorge de Lima, tomados como corpus deste estudo.

\section{ABSTRACT}

This text deals with aspects of Brazilian literary historiography as a starting point for a reflection on the place of children's literature in the scope of literary historiography and, later, the relevance of the playful, according to Huizinga (2004), in the aesthetic construction of these texts. Our objective is to address the aesthetic relevance of children's literature through the focus of poems by José Paulo Paes and Jorge de Lima, taken as a corpus of this study.
PALAVRAS-CHAVE:

Formação de leitores. Literatura.

Ensino.

Estética.

Historiografia.
KEYWORDS:

Formation of readers.

Literature.

Teaching.

Esthetics.

Historiography.

\footnotetext{
${ }^{1}$ Professor de Literatura brasileira na Universidade de Brasília - UnB. 
Compusemos este livro de leitura para o curso médio das escolas primárias do Brasil, a fim de ser ele o único livro destinado às classes desse curso; tal é, de fato, a indicação pedagógica aconselhada hoje: às primeiras classes do ensino primário não deve ser dado outro livro além do livro de leitura. ${ }^{2}$

\section{onsiderações iniciais}

A epígrafe que abre este estudo, retirada da obra Através do Brasil, de Olavo Bilac e Manuel Bonfim ${ }^{3}$, livro publicado em sua primeira edição 1910, é novamente utilizada por nós como epígrafe para um texto que aborda a especificidade do texto literário, aqui a literatura infanto-juvenil, e o ensino de literatura compreendido, neste estudo, como elementos inerentes ao processo de formação do leitor literário. Neste texto, pensamos os limites estéticos e na relevância temática da literatura infanto-juvenil na formação de leitores, tendo como ponto de partida a forma com que a historiografia literária apresenta obras literárias destinadas a leitores infantis e juvenis.

A ideia inicial de nossa discussão perscruta em que medida a historiografia literária brasileira trata a delimitação dos contornos estéticos e temáticos dos textos literários destinados a leitores jovens. Neste percurso, focalizaremos aspectos da diversidade estética e temática da literatura infanto-juvenil como, por exemplo, a presença do lúdico, do imaginário infantil, muitas vezes, via mobilização do jogo e do imaginário infantil como fontes estéticas importantes das obras que compõe nosso corpus de investigação.

A reflexão é organizada por dois caminhos metodológicos. No primeiro deles problematizamos a presença dos termos "infanto" e "juvenil" como traço depreciativo para a literatura destinada a jovens no âmbito historiográfico brasileiro. Comentaremos, sucintamente, alguns manuais de literatura brasileira em busca das referências a diversidade literária infanto-juvenil. O segundo é valorizar a relevância estética da literatura infanto-juvenil na tradição literária brasileira por meio de comentários dedicados a textos como "Convite" e "Cemitério", de José Paulo Paes e "O mundo do menino impossível", de Jorge de Lima, obras eleitas como corpus deste estudo.

\footnotetext{
2 BILAC, O; BONFIM, M. Através do Brasil: prática de língua portuguesa. 65 ed. Organização e notas Mariza Lajolo. São Paulo: Companhia das Letras, 2000, p. 63. ${ }^{3}$ Ibidem.
} 
Nossa preocupação é demonstrar a complexidade estética e a relevância dos textos e, com isso, problematizar a ideia de que textos infanto-juvenis apresentam "simplicidade" estética e baixa qualidade literária. Para nós, a relevância estética da diversidade literária, incluindo a literatura infanto-juvenil, compõe um espaço importante no âmbito da especificidade do literário na tradição literária no Brasil e, nesta aresta as reflexões aqui presentes põem em evidência a importância estética ligada às construções destinadas a leitores em formação no Brasil.

\section{Literatura infanto-juvenil: silêncio historiográfico}

No contexto da historiografia literária brasileira, muitos manuais como, por exemplo, História concisa da Literatura brasileira, de Alfredo Bosi $(1993)^{4}$, Formação da literatura brasileira, de Antonio Candido (2000) $)^{5}$ A Literatura no Brasil, de Afrânio Coutinho (1969), ${ }^{6}$ História da literatura brasileira, de Veríssimo $(1969)^{7}$, entre outras obras paradigmáticas, não tratam detidamente da diversidade de obras e autores brasileiros infanto-juvenis, o que, em nosso entendimento, contribui para um silêncio da crítica em relação à diversidade de textos destinados a este público, ou seja, leitores entre 08 e 14 anos de idade.

A construção dos paradigmas canônicos ligados a tradição literária são objetos recorrentes nos manuais supracitados, criando um processo de segmentação e apresentação de autores na construção do cânone literário brasileiro que tem reflexos na delimitação e seleção de obras literárias destinadas a leitores em formação. Na leitura destes manuais e compêndios literários um ponto específico nos tem chamado atenção: a ausência de referências, mesmo que sucintas, a diversidade e relevância da literatura infanto-juvenil produzida no Brasil.

Os textos listados na página anterior são manuais de literatura brasileira por retomarem um discurso classificatório dentro da tradição e, sobretudo, por pressupor um julgamento critico diante desta tradição, criando paradigmas a serem consultados na formação de futuros professores na área de Letras/linguística com reflexos em inúmeros cursos de Graduação distribuídos no território brasileiro. Os manuais e, também, compêndios criam um diálogo interno dentro do contexto da historiografia literária, o que reforça a abordagem de determinados autores como representantes na tradição literária da "boa' ou da "má" literatura no Brasil, postura que possibilita a compreensão destes livros como agentes se não de confirmação, mas de veiculação de valores ligados ao Canon.

\footnotetext{
${ }^{4}$ BOSI, A. História concisa da Literatura brasileira. 43 ed. São Paulo: Cultrix, 1993.

${ }^{5}$ CANDIDO, A. Formação da literatura brasileira. 23 ed. São Paulo: Iluminuras. 2000. Volume único.

${ }^{6}$ COUTINHO, A. A literatura no Brasil. São Paulo: s/ed, 1969.

${ }^{7}$ VERISSIMO, História da literatura brasileira. Porto Alegre: Global, 1969.
} 
A dificuldade de encontrarmos, nestes manuais, referências mais detidas sobre a diversidade literária infanto-juvenil compreende, em nosso entendimento, uma lacuna dentro de nossa tradição. Um exemplo deste processo é a ausência de referências a literatura infanto-juvenil em História concisa da literatura brasileira, de Bosi $(1993)^{8}$, um dos textos de maior circulação em contextos acadêmicos na área de Letras no Brasil e que se encontrava, em 1993, na 43ª edição.

Os manuais e compêndios citados anteriormente, resguardam a perspectiva fundadora de Candido $(1969)^{9}$, criando posicionamentos críticos retomados em larga medida pelos manuais de literatura brasileira e, talvez, somadas a textos como A literatura no Brasil, de Roncari $(1991)^{10}$ e Cereja $(2006)^{11}$ para citarmos alguns exemplos, entre muitos possíveis, estabelecem um conjunto de autores e obras que sintetizam questões já presentes em textos fundadores na perspectiva historiográfica brasileira como: A história da literatura no Brasil, de Silvio Romero $(1888)^{12}$ e, antes dele, Bosquejo da História da poesia brasileira, publicado por Joaquim Norberto de Sousa Silva originalmente em 1841 e, reeditado, sob organização de Roberto Acízelo de Souza, em 2002 ${ }^{13}$, sob o título de História da literatura brasileira e outros ensaios.

Estas obras, resguardadas as diferenças temporais, de certa forma, delimitam as reflexões inerentes aos principais manuais de literatura brasileira no que se refere à ausência de comentários detidos em relação à tradição literária infanto-juvenil, mesmo quando comentam, por exemplo, a obra de Monteiro Lobato. Regina Zilberman e Marisa Lajolo (1994, p.11) em uma das poucas obras que abordam historicamente a tradição literária infanto-juvenil comentam que

(...) se esse contraponto [valor estético do literário] não é comum, isto é, se todas as histórias literárias brasileiras até agora deixam de incluir em seu campo de estudo a literatura infantil, nunca é demais frisar o peso circunstancial que o adjunto infantil traz para a expressão literatura infantil. Ele define a destinação da obra; esta destinação, no entanto, não pode interferir no literário do texto. ${ }^{14}$

Seguindo o raciocínio das autoras, compreendemos que a ausência de referências aos textos literários infanto-juvenis nas principais "histórias literárias" brasileiras indica um silêncio da crítica face à relevância das obras infanto-juvenis, algo verificado na leitura atenta dos manuais e compêndios historiográficos listados até este momento do estudo.

\footnotetext{
${ }^{8}$ Op. Cit.

${ }^{9}$ Op. Cit.

${ }^{10}$ RONCARI, L. A literatura no Brasil: dos cronistas aos românticos. São Paulo: Iluminuras, 1991.

${ }^{11}$ CEREJA, W. R. Portuiguês e linguagens. 10 ed. São Paulo: FTD, 2006.

12 ROMERO, S. A história da literatura no Brasil. São Paulo: s/ed, 1888.

${ }^{13}$ NORBERTO. J. Bosquejo da História da poesia brasileira. In: SOUZA, R. A. História da literatura brasileira e outros ensaios. São Paulo: Mário Editor, 2002.
} 
A ausência de referências a esta diversidade nos manuais e compêndios acaba por refletir a opção historiográfica por centrar as discussões na chamada literatura "não-infantil". Pensamos, no entanto, que a diversidade literária infanto-juvenil adquire relevância estética que possibilita refletir sobre as potencialidades significativas destas obras. Para tanto, focalizaremos, nas próximas seções deste estudo, aspectos temáticos e estilísticos que problematizam a marginalidade da literatura infanto-juvenil nos limites historiográficos no Brasil.

Mesmo compreendendo a premência do detalhamento da diversidade literária infanto-juvenil focalizamos, neste estudo, a importância de não considerar os temos infantil e juvenil como um limitador das reflexões estéticas e temáticas inerentes ao aspecto literário das obras destinadas ao público jovem.

\section{O lúdico e o imaginário: traços críticos na leitura da literatura infanto- juvenil}

O que pretendemos, então, é aludir a qualidade estética das produções literárias destinadas a determinadas faixas etárias, neste escopo, leitores jovens circunscritos a faixa etária de 08 a $14 \operatorname{anos}^{15}$ e, ao final deste texto, retomar a ideia de que antes de serem obras destinadas a determinada faixa etária; são obras literárias e apresentam qualidade estéticas e relevância temática significativa.

Zilberman e Lajolo (1994, p. 11) ${ }^{16}$ compreendem que "as relações da literatura infantil [aqui infanto-juvenil] com a não-infantil são tão marcadas, quanto sutis", o que implica compreender que o julgamento de sua relevância deve ser feito para além do recorte etário de seus leitores; antes direcionada a qualidade de significações que apresentam. O que determina "as marcas sutis", em nosso entendimento, são a qualidade estética e relevância temática destes textos e, não, a delimitação de um público alvo, sobretudo, jovens em um mercado editorial cada vez mais agressivo para a literatura infanto-juvenil.

Elementos estéticos como a mobilização de temas próximos à

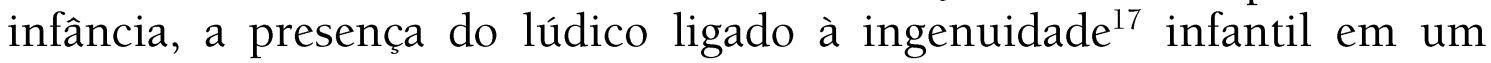

\footnotetext{
${ }^{15}$ Entendemos que a delimitação de textos infantis e infanto-juvenis acarreta um polêmico alinhamento a uma faixa etária específica, direcionando textos mais pueris a leitores entre 0 e 8 anos e textos ligados a temas como a descoberta da puberdade para leitores em uma faixa etária mais próxima dos 08 aos 14 anos. Como forma de evitar esta discussão, nos limites deste estudo, utilizaremos o adjetivo juvenil para pensar um conjunto amplo de textos destinados a leitores jovens. Nossa premissa é que uma vez compreendidos como obras literárias, a complexidade estética e temática dos textos amplia a delimitação etária comumente associada aos textos entendidos como obras literárias infantis e juvenis.

${ }^{16}$ ZILBERMAN, R.; LAJOLO, R. Literatura infantil: Histórias e histórias. São Paulo: Ática, 1994.

${ }^{17}$ A ideia da infância como uma fase etária na qual prevalece a ingenuidade e a pureza em uma relação menos tensiva face às convenções sociais. Este perfil ingênuo e puro, nos dias atuais, é fruto de reflexões uma vez que a dinâmica de acesso a informação e a constante exposição de jovens a conteúdos polêmicos como a fome, a diversidade sexual ou os inúmeros problemas sociais do século XX e XXI podem colocar a ideia de pureza em 102 | D O S S I Ê : LEITORES E LEITURAS NA CONTEMPORANEIDADE
} 
conjunto estético que responde as mobilização do imaginário infantil seriam paradigmas importantes a serem considerados na delimitação estética da literatura infanto-juvenil e que tomamos, neste texto, como pontos de discussão da literariedade em nosso corpus.

Para nós, pensar na diversidade estética e temática nas obras destinadas a leitores em formação compreende a valorização do texto literário destinado a jovens leitores como importantes na tradição literária brasileira. Focalizaremos como forma de delimitar o campo deste estudo a presença de procedimentos estéticos como a mobilização do lúdico, a presença da fantasia e do imaginário infantil na construção de níveis de leituras nas obras em discussão.

Para nós sobressai nas leituras da diversidade estética infantojuvenil sua qualidade literária ${ }^{18} \mathrm{e}$, com isso, pretendemos valorizar linhas de leitura que impliquem na qualidade intrínseca das obras em discussão neste estudo. O lúdico é um aspecto estilístico evocado como constante na delimitação de textos literários infanto-juvenis. Para Abramovick $(1991)^{19}$ a presença de jogos sonoros e uma dinâmica estilística de retomadas rítmicas criam na literatura para jovens uma ambiência sutil de leitura, o que contribui para a memorização e apreensão de sentidos complexos de forma mais harmônica em leitores iniciantes.

O poema "Convite" de José Paulo Paes é um exemplo da constante associação da literatura infantil a temas lúdicos, muitas vezes, evocados e aproximados à infância.

\section{Convite}

Poesia

é brincar com palavras

como se brinca

com bola, papagaio, pião.

Só que

bola, papagaio,pião

de tanto brincar

se gastam.

As palavras não:

quanto mais se brinca

com elas

mais novas ficam.

Como a água do rio

\footnotetext{
cheque. Preferimos não abordar a constante diminuição da ingenuidade como marca da pureza da infância nos dias atuais, mas chamamos a atenção de nossos leitores para a polêmica envolvendo o tema.

${ }^{18}$ Lembramos que em uma diversidade literária o valor da obra é sempre suscetível a qualidade estética e temática das obras e, assim como na literatura não-infanto-juvenil, existem textos de baixa qualidade, o que não deve indicar a rotulação de um gênero como inferior como parece ocorrer com a literatura infato-juvenil.

${ }^{19}$ ABRAMOVICK, F. Literatura infantil: gostosuras e bobices. São Paulo: Global, 1993.
} 
que é água sempre nova.

Como cada dia

que é sempre um novo dia.

Vamos brincar de poesia? ${ }^{20}$

No poema, o convite ao jogo, brincar com "bola, papagaio e pião", entra em consonância com a ideia de alinhamento ao lúdico na leitura dos textos infantis aproximando o poema à brincadeira pueril. Este paradigma, o da brincadeira, evoca o jogo infantil e remete ao lúdico aspecto temático entendido como um dos paradigmas para a interação do leitor com o texto. O lúdico, no entanto, é percebido como um caminho na leitura do texto de Paes, uma vez que, neste poema, o eu-lírico marca a distinção produzida pelo literário ao aproveitar os elementos da infância e conduzir o leitor para a reflexão de que na leitura literária as palavras são "sempre novas" e nunca se gastam, indicando que a comparação com a "brincadeira" é um caminho adotado para a construção de um primeiro contato com o texto; mas que indica via brincadeira o pano de fundo temático de traço metalinguístico inerente ao poema.

"Brincar" de poesia, como sugere o "Convite" feito pelo poema, é algo prazeroso, como nas brincadeiras da infância, mas que implica em descobertas e transformações, uma vez que o segundo elemento do símile evocado no poema, "rio" e suas águas "sempre novas", indica que "brincar" de poesia apresenta traços dos jogos infantis; mas, também, novas formas de enfrentamento do jogo, aqui o jogo estético inerente ao fazer literário uma vez que o eu-póetico brinca com "palavras".

As "palavras" não se gastam como os brinquedos, sendo, sempre, novas em uma alusão à construção metalinguística do poema que, nesta perspectiva, assume tons de reflexão estética, sobretudo ao pensamos o poema como um convite a compreender a complexidade da linguagem poética que, intencionalmente, retira os signos de sua compleição significativa habitual, para citarmos o conceito de singularização de Victor Chiklovisk (1986), e os lança em direção ao novo, metaforizado no poema na comparação às águas sempre novas do "rio" no poema de Paes ${ }^{21}$.

Esta percepção revela, em nível profundo, a intenção metalinguística subjacente ao poema de Paes e, com isso, alinha o poema à complexidade do gênero poético, mas estabelece o elo de interação via alusão à brincadeira infantil, indicando, por isso, como um leitor iniciante pode pensar o jogo como uma possibilidade de entrada no texto artístico. O lúdico é evocado pelo poema de José Paulo Paes por meio de um paralelismo estético que parece a primeira vista distante do jogo pueril

${ }^{20}$ PAES, J. P. Brincar de poesia. São Paulo: Global, 2007

${ }^{21}$ CHIKLOVISK, V. A arte como procedimento. In.: EIKHENBAUM, B. et al. Os formalistas russos. Porto Alegre: Global, 1986.

104 | D O S S I E : LEITORES E LEITURAS NA CONTEMPORANEIDADE 
evocado na primeira estrofe do poema; mas que se apresenta como paradigma para a construção da literariedade do texto de Paes ${ }^{22}$.

O jogo e o lúdico, no entanto, não é apenas motivado pela alegria da brincadeira infantil. Neste momento, lembramos Huizinga (2004) ao pensar o lúdico como inerente a complexidade do humano, pois para este autor "o fator lúdico propriamente dito, não é claramente expresso pela palavra ‘xywy." (2004, p. 35). Para Huizinga (2004) a brincadeira e o cômico atravessam um sentido irônico mais profundo que mobiliza o jogo e o lúdico ao fazem da palavra poética um espaço de transição entre um referente e sua projeção cômica.

Esta transversalidade irônica no lúdico provoca espaços de formação tensiva nos sentidos imediatamente ligados a raiz dos termos jogo e lúdico, sobretudo, na poesia, novamente recorrendo Huizinga (2004, p 147):

[O jogo é] uma atividade que se processa dentro de certos limites temporais e espaciais, segundo uma determinada ordem e um dado número de regras livremente aceitas, e fora da esfera da necessidade ou da utilidade material. $\mathrm{O}$ ambiente em que ele se desenrola é de arrebatamento e entusiasmo, e tornasse sagrado ou festivo de acordo com a circunstância. A ação é acompanhada por um sentimento de exaltação e tensão, e seguida por um estado de alegria e de distensão. ${ }^{23}$

"Brincar" de poesia, na acepção de $\mathrm{Paes}^{24}$, evocaria uma forma de abordagem do literário, sobretudo, da lírica em ambientes de formação de leitores jovens de forma a ampliar a leitura ingênua face à mensagem crítica subjacente ao literário e conduzir a uma reflexão mais ampla inerente ao texto artístico, aqui o literário. Esta percepção, de que a leitura literária indica descobertas de novos sentidos subjacentes aos signos linguísticos, cria um caminho de enfrentamento mais pueril à leitura literária e indica, também, o traço reflexivo direcionado a aparente alegria e ludicidade, o que entra em consonância com a ideia de expansão reflexiva, de "entusiasmo", conforme Huizinga $a^{25}$.

Lembramos que o literário, muitas vezes, é visto como distante do enfrentamento mais livre da leitura, sobretudo, quando pensamos na literatura canônica, por seu caráter hermético de fundo estético. $\mathrm{O}$ enfrentamento lúdico, no entanto, ameniza a aparente rigidez e revela procedimentos estéticos ligados a leitura literária de forma mais ampla, sobretudo, em ambiente escolar e de formação de eleitores. Em outros termos, o lúdico é, então, um caminho de entrada para a leitura do texto, mas indica, também, diálogos mais amplos em nível profundo.

\footnotetext{
${ }^{22}$ Op. Cit.

${ }^{23}$ HIZINGA, J. Homo ludens: o jogo como elemento da cultura. 5 ed. Tradução João Paulo Monteiro. São Paulo: Perspectiva, 2004

${ }^{24}$ Op. Cit.

${ }^{25}$ Op. Cit.
}

105 | D O S S I E : LEITORES E LEITURAS NA CONTEMPORANEIDADE 


\section{Para Silva e Silveira (2013, p. 93)}

no cotidiano da escola, mais especificamente no da sala de aula, os gêneros literários têm exercido o papel de apêndice da gramática e do ensino; pretexto para interpretações prontas e acabadas, e, quando não, vistos como mero passatempo. Outro equívoco é associar a leitura literária ao mero prazer, como se prazer ou desprazer pela leitura não fosse uma produção social e cultural, pois ninguém nasce gostando ou não de ler; tendo prazer ou não pela leitura. ${ }^{26}$

O aparente distanciamento de leitores face às obras literárias prejudica, concordando com Silva e Silveira ${ }^{27}$, a construção de leitores autônomos, muitas vezes, pela dificuldade de leitura do literário para além da ideia de "passatempo" e "prazer" desvinculados de uma linha reflexiva mais ampla.

Segundo Brasil (1997) deve-se compreender uma formação via literário que amplie no domínio da leitura literária a formação do sujeito crítico e reflexivo, pois

formar um leitor competente supõe formar alguém que compreenda o que lê; que possa aprender a ler também o que não está escrito, identificando elementos implícitos; que estabeleça relações entre o texto que lê e outros textos já lidos; que saiba que vários sentidos podem ser atribuídos a um texto; que consiga justificar e validar a sua leitura a partir da localização de elementos discursivos que permitam fazê-lo. ${ }^{28}$

"Convite", nesta linha de leitura, é uma provocação ao leitor literário que levado primeiramente pelo brincar de ler, o faz por meio da descoberta de distinções entre a brincadeira que o poema vai traçando e o hermético da linguagem poética que vai criando paralelos reflexivos na montagem/elaboração do artístico. Em outros termos, ao mesmo tempo que a leitura do poema mobiliza a brincadeira é, também, um exercício crítico de leitura literária uma vez que o poema alude a necessidade de distanciar o brincar com "bola, papagaio, pião" e o fazer poético que incorpora "palavras" via lúdico.

Acreditamos que a leitura do literário deve, antes de tudo, criar leitores propensos a desvendar caminhos subjacentes na estrutura profunda da obra artística, o que conduz a processos reflexivos de leitura da obra e sua compreensão indica a fruição do texto, conforme proposto por Barthes ${ }^{29}$. Tal postura amplia a percepção do aspecto artístico e valoriza o traço desautomatizador da arte ao proporcionar aos jovens

\footnotetext{
${ }^{26}$ SILVA, Antonieta M. O. de; SILVEIRA, Maria Inez M. Leitura para Fruição e Letramento Literário: Desafios e Possibilidades na Formação de Leitores. Revista Eletrônica de Educação de Alagoas. Volume 01, número 01, $2^{\circ}$ semestre 2013, p. 92-101. Disponível em: <http://www.educacao.al.gov.br/reduc/edicoes/la-edicao/artigos/reducla-edicao/LETRAMENTO\%20LITERARIO\%20NA\%20ESCOLA Antonieta\%20Silva Maria\%20Silveira.pdf>.

Acesso: setembro de 2013

${ }^{27}$ Ibidem

${ }^{28}$ BRASIL. MEC. Parâmetros Curriculares Nacionais: Ensino Médio. Brasília: MEC/SEF,1999.

${ }^{29}$ BARTHES, R. O prazer do texto. São Paulo: Paz e Terra, 1998.

106 | D O S S I E : LEITORES E LEITURAS NA CONTEMPORANEIDADE
} 
leitores o convívio prazeroso com a leitura, mas, ao mesmo tempo, possibilitar, pela leitura da palavra, a ampliação da leitura de mundo, concordando, aqui, com Lajolo (1993). ${ }^{30}$

No poema "Cemitério", de José Paulo Paes temos um exemplo deste processo.

\author{
Cemitério \\ 1 \\ A/qui/jaz/ um/le/ão - A \\ $\mathrm{Cha} / \mathrm{ma} / \mathrm{do} / \mathrm{Au} / \mathrm{gus} /$ to. $-\mathrm{B}$ \\ Deuum urrotão forte, $-\mathrm{C}$ \\ mas um urro tão forte, - C \\ que morreu de susto. - B
}

2

Aqui jaz uma pulga

chamada Cida.

Desgostosa da vida, tomou inseticida:

Era uma pulga suiCida.

3

Aqui jaz um morcego que morreu de amor por outro morcego. Desse amor arrenego: amor cego, o de morcego!

4

Neste túmulo vazio jaz um bicho sem nome. Bicho mais impróprio! tinha tanta fome, que comeu-se a si próprio. ${ }^{31}$

O poema de José Paulo Paes ao dialogar com a forma fixa do epitáfio e utilizar a redondilha menor em um amplo processo de cacofonia sonora mobiliza rimas internas para criar o efeito cômico e produzir o riso, muito próximo do jogo lúdico, conforme Huizinga (2004), criando, assim, uma tangente enunciativa que esbarra nas qualidades intrínsecas de cada personagem evocado no poema.

Diferente do perfil eufórico do epitáfio que opta pela descrição harmônica do morto em elogios quase sempre pueris face à realidade

\footnotetext{
${ }^{30}$ LAJOLO, M. Do mundo da leitura para a leitura do mundo. São Paulo: Ática, 1993.

${ }^{31}$ Op. Cit.

107 | D O S S I Ê : LEITORES E LEITURAS NA CONTEMPORANEIDADE
} 
imediata; o tom positivo do epitáfio ocupa lugar deslocado no poema de José Paulo Paes ${ }^{32}$. O leão "Augusto", a pulga "Cida", o "Morcego" e o "bicho sem nome" encontram na descrição da fragilidade inerente a cada uma das trajetórias individuais evocadas um espaço tensivo, quando compreendidos na aparente dicção fluída que o poema adquire ocupam ponto irônico em relação a propensa bondade humana geralmente construída nos elogios dos epitáfios.

Cada verso, neste sentido, dialoga com a ilusão/ironia de que a vida é boa e as ações humanas são dignas de epitáfios bondosos e bem humorados. Esta flexibilização dos elogios aponta para a fragilidade e efemeridade da vida e, com isso, expõe a trajetória frágil e polêmica de cada um dos personagens. A presença da sonoridade e das cacofonias, principalmente, pela harmonia sonora trazida pela redondilha menor, deixa implícito o tom burlesco que o poema evoca.

O leão Augusto, morre de susto em decorrência de seu próprio "urro", a pulga suicida e o morcego que morre de amores por outro "morcego",em seu amor "arrenego", conduzem em nível profundo para a percepção de que o homem, "bicho sem nome" que come a si "próprio" no poema são produtos de uma sociedade que esconde seus problemas e se preocupa exageradamente com si mesmo. A "pulga Cida" e seu tom autodestrutivo encontra eco na imagem do "morcego" que encontra a morte prematura "pela incompreensão de si mesmo e do outro". Tanto "Cida" quanto o "morcego" aludem à efemeridade da vida e a influência de traços alheios a profundidade ontológica associada ao sujeito humano antropomorfizado ironicamente nos personagens do poema.

A presença de temas tabus como o homossexualismo, "morcego", do egoísmo e egocentrismo, sobretudo em relações afetivas, "Cida" e "Augusto", levam ao processo decadente que assola os personagens do poema, metaforizadas na imagem decadente do "bicho que come a si próprio" no texto. Esta problematização ontológica cria o diálogo crítico com a fragilidade lúdica ligada a brincadeira pueril no poema de José Paulo Paes, aspecto intensificado pelas cacofonias e rimas do texto.

O riso solto, neste sentido, é interrompido pela percepção de que o poema alude aos problemas individuais da natureza humana e, com isso, cria uma tangente significativa face à fragilidade significativa do epitáfio que, quase sempre, opta por um recorte positivo da vida do homem, transformado, no poema, ironicamente, sinônimo de morte, em "Cemitério". A percepção de uma reflexão diante do traço destrutivo próprio ao ser humano, propenso a devorar-se a si "próprio" tem como resultado, no poema de Paes, a expressão de sua natureza "imprópria", ou seja, uma alusão eufêmica ao conjunto de falhas éticas e morais que o levam, o homem, ao silêncio e ao abandono do "túmulo vazio".

${ }^{32}$ Ibidem.

108 | D O S S I Ê : LEITORES E LEITURAS NA CONTEMPORANEIDADE 
Ao adotar uma linha inventiva de traço polêmica o poema "Cemitério" parece contribuir para nossa reflexão quando pensamos na necessidade de leitura crítica dos textos formativos da tradição literária infanto-juvenil no Brasil para além do traço ingênuo frequentemente associado à brincadeira infantil.

$\mathrm{O}$ riso e o humor, novamente evocando Huizinga (2004) ${ }^{33}$, contribuem para nossa reflexão, pois para além do riso cômico teríamos na literatura e, em grande parte das obras de expressão artística, o traço reflexivo que contribui para a formação de leitores críticos. A eminente indicação de fragilidade humana via riso no poema "Cemitério" indica a profundidade enunciativa que a leitura do literário possibilita a leitores em formação.

O poema "O mundo do menino impossível", de Jorge de lima (1996, p. 25$)^{34}$ é outro exemplo da presença de elementos críticos em diálogo com o aspecto lúdico na literatura infanto-juvenil.

\section{O mundo do menino impossível}

Fim da tarde, boquinha da noite

com as primeiras estrelas

e os derradeiros sinos.

Entre as estrelas e lá detrás da igreja,

surge a lua cheia

para chorar com os poetas.

E vão dormir as duas coisas novas desse mundo:

o sol e os meninos.

Mas ainda vela

o menino impossível

aí do lado

enquanto todas as crianças mansas

dormem

acalentadas

por Mãe-negra Noite.

O menino impossível

que destruiu

os brinquedos perfeitos

que os vovós lhe deram:

o urso de Nürnberg,

o velho barbado jugoeslavo,

aspoupées de Paris aux

cheveux crêpés,

o carrinho português

feito de folha-de-flandres,

\footnotetext{
33 Op. Cit.

${ }^{34}$ LIMA, J. Poesia reunida. São Paulo: FTD, 1996
} 
a caixa de música checoslovaca,

o polichinelo italiano

made in England,

o trem de ferro de U. S. A.

e o macaco brasileiro

de Buenos Aires

moviendo la cola y la cabeza.

O menino impossível

que destruiu até

os soldados de chumbo de Moscou

e furou os olhos de um Papá Noel,

brinca com sabugos de milho,

caixas vazias,

tacos de pau,

pedrinhas brancas do rio...

"Faz de conta que os sabugos

são bois..."

"Faz de conta..."

"Faz de conta..."

E os sabugos de milho

mugem como bois de verdade...

e os tacos que deveriam ser

soldadinhos de chumbo são

cangaceiros de chapéus de couro...

E as pedrinhas balem!

Coitadinhas das ovelhas mansas

longe das mães

presas nos currais de papelão!

É boquinha da noite

no mundo que o menino impossível

povoou sozinho!

A mamãe cochila

O papai cabeceia.

O relógio badala.

E vem descendo

uma noite encantada

da lâmpada que expira

lentamente

na parede da sala...

O menino pois a testa

e sonha dentro da noite quieta

da lâmpada apagada

com o mundo maravilhoso

que ele tirou do nada... 
Xô! Xô! Pavão!

Sai de cima do telhado

Deixa o menino dormir

Seu soninho sossegado!

O poema "O mundo do menino impossível" coloca em discussão a situação fragilizada de um menino de rua que no "fim da tarde, boquinha da noite/ com as primeiras estrelas e os derradeiros sinos" dorme entre "estrelas" atrás "da igreja". A "lua cheia" que surge "para chorar com os poetas" indica que a inocência dorme com "o sol e os meninos", mas encontra no imaginário do menino de rua que dorme atrás da igreja uma possibilidade de reflexão face à situação fragilizada que vivencia.

O "menino impossível" que brinca com "bois feitos de sabugos de milho" tem como imagens da infância o sofrimento. Este, metaforizado nos "ursos de Nürnberg", metáforas dos brinquedos esquecidos e destruídos encontra na alusão ao julgamento nazista de 1945 e na constante industrialização do século XX associada às imagens deslocadas de uma infância impossível, a suspensão da inocência pueril de um "menino impossível e seus brinquedos eclipsados pela noite, dando pano de fundo para os sonhos do menino como caminho inventivo possível para a presença da ingenuidade infantil: "E os sabugos de milho/ mugem como bois de verdade...".

A impossibilidade da quietude da infância, ironia que percorre o poema, assolada as imagens caóticas do mundo, encontrando refúgio no imaginário do menino em sua "boquinha da noite/ no mundo que o menino impossível/ povoou sozinho!". Neste mundo imaginário, o lúdico é aspecto de repouso, mas encontra na impossibilidade concreta, centrada na imagem do menino de rua e sua imagem de silêncio, o caminho crítico da denúncia ao abandono infantil.

As referências a "Mãe Preta", associada à noite e sua irônica proteção materna, "por Mãe-negra Noite" encontra nas cantigas de ninar, "Xô, Xô pavão/ Deixa o menino dormir sossegado" e no imaginário infantil o traço lúdico e pueril com o qual o menino só pode sonhar no poema. A compreensão da fragilidade da inocência contida no "sono do menino" ameaçado pelas imagens caóticas da Segunda Grande Guerra e do mundo que o envolve é um eufemismo às marcas de violência ao esvaziamento da pureza infantil que resiste, apenas, no sonho do menino de rua que dorme aos olhos do poeta.

O imaginário, "faz de conta", é a saída possível para o mundo do menino impossível. O concreto, imagem do abandono e do sofrimento, evocada explicitamente na quarta estrofe e sintetiza na alusão a "folha de flandres" e nas referências aos abusos do holocausto impingem ao "menino impossível" sua condição de sonho como possibilidade para enfrentar a realidade agressiva que o cerca. Esta, metaforizada na alusão à "noite" de estrelas, cria a possibilidade de preservação pueril, concretizada 
na quarta estrofe, mas ambientada em uma imagem de desolamento, ou seja, "o menino que destruiu" seus brinquedos; resiste na imaginação e sonha a casa, a mãe e a luz na parede se apagando como uma imagem distante, por isso, impossível.

O contraponto ao real é, portanto, o onírico, sonhar com uma casa possível, na imagem da noite que o envolve. O "menino impossível" encontra na noite um refúgio, posto que envolta pela imaginação. $O$ imaginário, sonho da família e da casa, e o lúdico, "fazer de conta", "transformar sabugos em bois", indica a impossibilidade de "dormir sossegado"; mas é, também, índice de refúgio para a tensão do mundo em um poema que apela para a necessidade de regresso a pureza infantil em um espaço de proteção face à solidão e o abandono.

O imaginário é, portanto, a saída "possível" para a materialidade do menino, por isso, no poema, um "menino" projeta seus sonhos de infância como possibilidade de construção eufórica, porém, de forma irônica uma vez que "impossível". O caminho crítico indicado no poema aponta, então, para a valorização do imaginário e do lúdico como saída para o menino "impossível" e, neste percurso, nos indica que o lúdico e o imaginário infantil não são completamente absorvidos pelo caos social evocado no poema, principalmente, na terceira e quarta estrofe.

"O mundo do menino impossível", de Jorge de Lima indica uma possibilidade de permanência, ou seja, é no poema que a "impossibilidade" do menino encontra uma possibilidade: o sonho de proteção, de uma mãe e da infância e suas brincadeiras. Para nós a compreensão de que o lúdico e o imaginário são imanentes a literatura infanto-juvenil não implica, portanto, compreender as obras como desprovidas de teor crítico/reflexivo face à realidade circundante.

Concordamos com Lajolo (1993, p. 108) ao entendemos que

a discussão sobre leitura, principalmente sobre a leitura numa sociedade que pretende democratizar-se, começa dizendo que os profissionais mais diretamente responsáveis pela iniciação na leitura devem ser bons leitores. Um professor precisa gostar de ler, precisa ler muito, precisa envolver-se com o que lê..$^{35}$

Nossa preocupação, neste estudo, foi refletir sobre a importância da leitura crítica de textos infantis ao pensar a tensão temática inerente a literatura infanto-juvenil como importante processo de manipulação estética do lúdico e do imaginário infantil.

Chartier (2002) ${ }^{36}$ compreende que a formação de um leitor passa pelo processo de incorporação de textos em uma interação crítica o que, progressivamente, leva a reflexão e a formação humana como resultado

${ }^{35}$ Op. Cit.

${ }^{36}$ CHARTIER, R. Sobre a leitura. In. Revista Nova Escola. São Paulo: Ática, 2002. 
das diferentes leituras de mundo provocadas pela interação leitor/mundo via texto.

A literatura, nesse contexto, contribui para a construção de textos significativos não só em termos linguísticos, ou seja, ligados a competência textual do escrevente, mas como possibilidade de produzir enunciados que dinamizem sua formação cultural em um diálogo contínuo com a complexidade social ao entrar em contato com os diferentes recortes históricos e culturais presentes nas obras literárias incluindo, as destinadas a leitores jovens.

\section{Considerações finais}

As reflexões presentes neste texto indicam que a apresentação de textos literários infanto-juvenis a leitores em formação é um caminho para a formação de leitores autônomos. Compreendemos, naturalmente, as dificuldades que envolvem a apresentação do literário em um espaço de tempo reduzido para o conteúdo de literatura na Educação Básica, quase sempre, fundido a conteúdos de Língua Portuguesa e restrito a uma ou, no máximo, duas horas semanais em grande parte das regiões federativas do Brasil. Entendemos, no entanto, que a dificuldade de enfrentamento do literário em ambiente escolar na Educação Básica encontra no traço lúdico e na manipulação estética do imaginário infantil um caminho para reorganizar a relação entre o texto literário e jovens leitores.

Pensando nessa aparente contradição, tratar de forma crítica e reflexiva o objeto literário em um tempo reduzido; aludimos, neste estudo, que ao atestar a especificidade estética de produções literárias o lúdico e a brincadeira é uma possibilidade de reflexão face ao literário. Acreditamos, como forma de finalizar nossas reflexões, que a leitura literária contribui à formação de leitores de forma ampla e, nesse sentido, que estudos mais detidos que focalizem a qualidade estética de textos literários infantojuvenis é "caminho" importante para a valorização do literário em um contexto mais amplo e, com isso, continuar percorrendo o intrincado labirinto da leitura e seus (des)caminhos, vistos aqui como metáfora da complexidade da leitura literária em ambiente escolar. 